\title{
The Readiness of Banks in Knowledge Management: A Study of Three Private Commercial Banks in Bangladesh
}

\section{Rashed MS*}

Faculty of Business Administration, Department of Management, University of Chittagong, Bangladesh

\begin{abstract}
Doing business in and with China has become much easier than it was decades ago. But doing business does not guarantee that everyone will make money. China has embarked an unprecedented economic growth since its economic reforms (1978) three decades ago, rising to become the world's second largest economy today and will become largest by 2020. A new path under the 12th Five-Year plan (2011-2015) towards sustainable and balanced development, alongside a focus on boosting domestic consumption is opening new opportunities in china for continued industrial innovation and business expansion. China still holds a number of challenging areas for foreign investors. Beside the cultural and language challenge, business men might be faced foreign exchange restrictions, anti-trust laws, intellectual property rights and diversified people in all over china. China is also facing raw material shortages, lack of infrastructure, corruption in many sectors, growing income inequality, environment pollution and maintain stability in the society. Despite the challenges, many factors contribute to a positive business environment in China. Many gaps that exist in China provide opportunities for businesses to fill these gaps. In order to overcome many challenges, there are different forms of business might be opened by foreign investors in China like equity joint ventures, cooperative joint venture, wholly foreign owned enterprises, joint stock companies, foreign enterprises, branches of foreign enterprises and so on.
\end{abstract}

Keywords: Readiness; Banks; Knowledge Management; Commercial Banks; Bangladesh

\section{Introduction}

Organization especially banks are constantly under intense competition due to globalization and innovation and tremendous market pressures [1]. Banking sector in Bangladesh is caught in trapped by high interest rate, excess of liquidity and reduction of growth of credit to private sector, intermediating lower investment, coupled with poor risk management, fraudulence, driven by captured governance and lax oversight resulting in lower profitability to the shareholders. Credit and risk management status is also not satisfactory in the banking sector.

Asset quality in the state-owned commercial banks (SCBs) deteriorated in 2014 due to political unrest, poor lending decisions and change in loan classification standards (WB, 2014). Banks can improve this current situation by two ways: increasing the supervision of the Bangladesh Bank (Central Bank of Bangladesh) and improving the relationship and trust with current and potential customers. Maintaining good relationship with customers need customer knowledge about product and services and customer knowledge is also required for new product development and future innovation. Moreover, the banks that survive will have full and accurate knowledge of their customers' profiles (i.e. needs, wants, demands) as well as an understanding that will allow them to identify macro-environmental trends in a rapidly changing environment [2].

Since 1990, knowledge is considered as an essential strategic resource that enables firms to sustain a competitive advantage in a dynamic market environment $[3,4]$. Business organizations have an inherent interest in using both the business knowledge owned by the organization, and the personal knowledge of their employees. Business knowledge is practical knowledge that is related with knowledge for management, production, service and innovation in industries, rather than broader social and scientific knowledge [5]. Since knowledge resides within the brain of employees, firms develop various strategies to create organizational knowledge through leveraging employees' knowledge [6]. In future, the only sustainable competitive advantage will be the creation of collective and tacit knowledge that adds the greatest value to an organization [7].

Knowledge management (KM) initiatives that create business value are a major focus for many organizations. While academics often couch KM success in terms of process outcomes, some argue that the organizational outcomes perspective of KM success held by many practitioners is clearer, where KM success is tied to its impact on organizational performance $[1,8]$. The success or failure of KM depends on how effectively an organization's members share and use their knowledge. Thus management of knowledge is at the core of organization's business growth. In the light of this reflection this special issue pays attention to two main perspectives. First, recognizing that knowledge, likewise any other organization's resource, needs management means to support its allocation and development, the frameworks and tools aiming to identify, manage and assess the critical knowledge resources for growth are focused on. Second, acknowledging that the translation of knowledge into business outcomes requires management mechanisms, and then considering the knowledge processes grounding the improvement of performance [9].

Cader et al. mentioned that successful identification of trends requires continuous implementation of market research as well as investment in research and development - for this will nurture the generation of a sustained stream of competitive and innovative products and services that in turn foster growth and profit [2]. In the

*Corresponding author: Rashed MS, Assistant Professor, Faculty of Business Administration, Department of Management, University of Chittagong, Bangladesh, Tel: 8613585927060; E-mail: rashed_mgt@yahoo.com

Received February 03, 2016; Accepted March 31, 2016; Published April 10, 2016

Citation: Rashed MS (2016) The Readiness of Banks in Knowledge Management: A Study of Three Private Commercial Banks in Bangladesh. J Bus Fin Aff 5: 181. doi:10.4172/2167-0234.1000181

Copyright: (c) 2016 Rashed MS. This is an open-access article distributed under the terms of the Creative Commons Attribution License, which permits unrestricted use, distribution, and reproduction in any medium, provided the original author and source are credited. 
current macro-environment, it is imperative that banks be able to transform research-generated data into information which can then be turned into knowledge. This knowledge can then enable decision makers to engage in appropriate action. This process is a fundamental principle of KM.

This research identified gaps in KM implementation and utilization in three banks in the Bangladesh. It also sought to ascertain if there exist differences in KM implementation and utilization between Islamic and conventional banks and, if so, what these may be.

\section{Knowledge}

A common explanation in the KM literature is that data is combined to form information and information is combined to create knowledge. Any discrete facts can be defined as data. But there is no specific definition for information and knowledge. Information has been defined as data with special purpose and relevance [10], data that makes a difference [11], data in context [12], and a result of analysing and interpreting data that carries meaning [13]. The meaning of the word "knowledge" is even subject to a number of different interpretations. Knowledge is not tantamount with information [14]. Knowledge has been defined as justified true belief (Plato), a dynamic human process of justifying personal belief toward the truth [15], a fluid mix of framed experiences, values, contextual information and expert insight [16], power to act and make decisions [17], professional expertise appropriate for the domain [13], integrated information in context [12]. Knowledge can be classified as subjective or objective; or explicit or tacit/implicit. Polanyi first identified human knowledge into two dimensions: explicit knowledge (formalized and written knowledge, expressed in the form of data, scientific formulae, specifications, manuals and textbooks) and tacit knowledge (action-based knowledge that resides within an individual and hard to transfer) [18]. Moreover, knowledge is not gained by an object flow of events and the necessary outcome of a determined scientific process, but also some of the human conditions as the sense of beauty and passion [18]. However, tacit and implicit knowledge are not mutually exclusive efforts to bring them out in an organization that will require the allocation of resources and can produce unexpected outcomes [19].

\section{Knowledge management}

Knowledge Management (KM) is not simply about recording and manipulating explicit knowledge, but needs to address that, which is implicit, and from which benefit can therefore be derived only through process rather than content [5]. KM is primarily a business concept that can bring increased profitability for commercial organizations [20]. In addition, KM is the identification of "capabilities" or "resources" that allow firms to recognize, create, transform, and distribute knowledge within the organization. The most common definition for $\mathrm{KM}$ as:

"KM can be defined as an integrated approach to identifying, capturing, retrieving, sharing, and evaluating an enterprise's information resources. These information resources include databases, documents, policies and procedures, as well as the un-captured tacit expertise and experience stored in individual employee's heads" [21]. Moreover, KM can be seen as a strategic attempt to capture information and experience of employees and customers and store them in the database, and later disseminate this knowledge to gain more benefit and competitive advantage. However, organizations are acquiring skills and capability in handling internal knowledge and also applying it towards the achievement of the organizational goals, they are looking towards new sources of knowledge that are not necessarily found within the boundaries of the firm" [22].
$\mathrm{KM}$ and its application are considered an imperative for achieving business success [8]. KM is a set of procedures and managerial tools developed to capture, acquire, organize and communicate both tacit and explicit knowledge of employees so that other employees can utilize them to make their work more effective and productive and maximize organization knowledge [23]. KM in business organizations need to manage the activities of knowledge workers or the transformation and interaction of organizational static and dynamic knowledge for products, services, and practical process innovation and, at the same time, creating new or justifying existing organizational systematic knowledge [5]. The purpose of $\mathrm{KM}$ is to create a common space for individuals to interact for exchanging and creating knowledge [24-26].

$\mathrm{KM}$ applications help organizations to improve their performance and competitiveness [27-29]. Developing and maintaining KM is vital to firm long-term survival and success. KM can gradually transform individual knowledge into group and organizational knowledge, in turn, improving the stock and flow of firm knowledge. Consequently, firms invest in KM particularly to accumulate business management experience and develop a sustainable competitive advantage [30,31].

\section{Knowledge management in banking sector}

Today's banking system are overwhelm in greater risks arising from the global economy recession. These banks are struggling to emerge from the economic recession and depression by capturing and retaining much more loyal and stable customers in the financial stage [32]. The banking and financial sectors are fundamental drivers of innovation. Knowledge intensive organizations like these are increasingly implementing KMS to drive forward their strategies and improve performance [8]. The benefits are significant related to different encouragements in performance such as better decision making, improving the customer relationship management, create new value through new services (innovations) and creating additional businesses [28]. Delivering unique products/services to customers helps to improve customer satisfaction and sales volume, and so firms have observed the influence of knowledge development over performance $[6,27,33]$. KM implementation has provided various interrelated benefits to the banks, rendering to utilize its resources efficiently and effectively [27]. The result shown that effective implementation of knowledge management application provides interrelated and multifaceted benefits such as knowledge activities performance, process performance, employee performance, market performance, and organizational performance that converted to organizational performance by affecting each other directly and indirectly in banks. Banks today, however, face many challenges which include large scale competition for customer's deposits, loans, increasing customer demands, shuddering profit limits, and the need to keep up with the new financial technologies that will ease banking operations [32].

\section{Knowledge infrastructure capability}

Supportive and effective knowledge infrastructure is precursor of KM initiatives [34,35]. Generally, infrastructure management provides the infrastructural environment either depends on IT or non-IT that supports knowledge creation and sharing capabilities [36]. KM infrastructure can be defined as technical, structural, and cultural factors that enable the maximization of social capital for KM [37]. In addition, Lee at al. suggested that KM infrastructure is composed of four groups of KM enablers: culture, structure, management and technology [38]. 


\section{IT Support/Technology}

Technology, especially so-called information technology (IT) that enable the integration of information and knowledge in the organization as well as the creation, transfer, storage and safekeeping of the firm's knowledge resource [31]. Gold et al, stated that "Technology comprises a crucial element of the structural dimension needed to mobilize social capital for the creation of new knowledge" [32]. IT plays a pivotal role in the knowledge transferring processes by which organizational members are encouraging to use and apply knowledge and to take action beneficially and productively that can build the whole point of KM [39-41]. IT is not alone linked to KM infrastructure but when combined with other knowledge resources such as knowledge acquisition and knowledge application processes, which may will enhance organizational performance [42].

IT affects the KM process in two significant ways. First, the database and data warehousing technology enables rapid collection, storage, and exchange of knowledge on a large scale. Various types of knowledge can be stored and accessed, including images, audio, and video [43], thereby assisting the knowledge sharing process [44]. Second, groupware and workflow technology facilitates the integration of fragmented flows of knowledge [37,45].

Thus, IT supports KM processes such as knowledge creation, collaboration, communication, searching, access, and systematic storage $[37,43,44]$. IT contributes to the improvement of organizational learning and performance by facilitating KM processes [46]. "Best practices" embedded in IT can support learning in order to perform work processes effectively. IT based KM processes allow increases in the breadth and depth in knowledge creation, storage, transfer, and utilization [24]. Therefore, the broader the scope of the IT infrastructure is, the stronger the capability of KM processes is. Thus, this leads to the hypothesis:

\section{IT support positively affects knowledge process capabilities}

Organizational culture: A knowledge-friendly culture is regarded as one of the most important factors impacting $\mathrm{KM}$ and the outcomes from its use $[16,47,48]$. Organizational culture in KM plays a pivotal role in knowledge creation because it effects how members learn, acquire, and share knowledge [49]. Organizational cultures represent the character of an organization, which directs its employees' dayto-day working relationships and guides them on how to behave and communicate within the organization, as well as guiding how the company hierarchy is built [50]. Thus, an emphasis on individual learning leads to an increased expectation of knowledge creation in organizations. Therefore, organizations should focus on both individual learning and group learning in order to increase organizational performance through learning [51]. Creative organizational learning depends on the ability of organizational members to make existing knowledge invalid and adjust the understanding of new environments through acquiring new knowledge [52]. Hence, the following hypothesis can be proposed:

\section{Culture positively affects knowledge process capabilities}

Organizational structure: Organizational structure comprises the organizational hierarchy, rules and regulations, and reporting relationships and is considered a means of co-ordination and control whereby organizational actors can be directed towards organizational effectiveness [53]. Changes in an organization's structure, such as moving from hierarchical to flatter networked forms, are essential for the effective transfer and creation of knowledge in the organization
$[3,15,37,54]$. Sharing and collaborating across boundaries within the organization and across the supply chain can be facilitated if the organizational structures are designed for flexibility [37]. Thus, the more decentralized the organization structure is, the greater the possible knowledge creation and utilization is. Thus, the following hypothesis can be suggested:

\section{Organization structure is positively affects knowledge process capabilities}

Top management support: Top management support is considered a prerequisite for successful implementation of KM $[55,56]$. Top management support means the degree to which support provided from top to encourage employees to share their knowledge. Knowledge transfer among levels may be troubled when top management fails to communicate the importance of KM to their employees [57]. Thus, top management should undertake an active and compensating role to stimulate knowledge creation and transfer [58].

The following hypothesis is proposed "Top management support positively affects knowledge process capabilities".

\section{Conclusions}

First, a new IT architecture is needed that includes new languages, categories, and metaphors for identifying and accounting for skills and competencies oriented toward problem-solving and representation, rather than output and transactions. Second, there needs to be a new organizational architecture that is more social, transparent, open, flexible, and respectful of the individual users. That is, both technological and organizational initiatives are needed; if aligned and integrated, they can provide a comprehensive infrastructure to support knowledge management processes productively [14].

The conclusion of our work is a set of recommendations to the government seeking to implement successful employee portals and avoid these barriers, which are: Hector M. Perez Feijoo et al. [59].

- To provide security guarantees to its employees: explicit confidentiality protection and implementation of measures to make visible the collective security involved.

- Increase the usability of the system: the training activities for understanding the functioning of system and the benefits it provides will improve the perception of the ease of use and its usefulness in general.

- Ensure necessary support about the functioning of the Portal: The resources allocated to the portal and the transparency and information on them, improve the image of the Administration and their employees are more willing to cooperate in the implementation.

- Improving the innovative ability of users: they need to have access to training resources and knowledge generated throughout the organization.

- Changing the internal processes of government agencies to integrate the portal naturally into the work of employees and not being perceived as a strange or disruptive element of natural procedures.

Administration that seeks to implement a successful system has to provide security for its employees, ensuring the confidentiality and taking action to make this security visible for involved groups. Also, training actions about the understanding of the functioning of the 
system and the benefits that it provides, will enhance the perception about the ease of use and its overall usefulness. In the same vein the resources allocated to the portal and the transparency and information on them, improve the image of the Administration and their employees are more willing to cooperate in the implementation. Additionally, to enhance the innovative capacity of individuals is necessary the access to training resources and knowledge generated throughout the organization. Finally, and as we have repeatedly pointed out, a change in the internal processes of government is needed for the portal integrates naturally into the work of employees and not being perceived as a strange or disruptive element of natural processes of work.

\section{References}

1. Mousavizadeh M, Ryan S, Harden G, Windsor J (2015) Knowledge managemen and the creation of business value. Journal of Computer Information Systems 55: $35-45$

2. Cader Y, O'Neill KK, Blooshi AA, Al Shouq AAB, Fadaaq BHM, Ali FG (2013) Knowledge management in Islamic and conventional banks in the United Arab Emirates. Management Research Review 36: 388-399.

3. Grant RM (1996) Towards a knowledge-based theory of the firm. Strategic Management Journal 17: 109-122.

4. Spender JC (1998) Pluralist epistemology and the knowledge-based theory of the firm. Organization 5: 233-256.

5. Gao F, Li M, Clarke S (2008) Knowledge, management, and knowledge management in business operations. Journal of Knowledge Management 12 3-17.

6. Bogner WC, Bansal P (2007) Knowledge Management as the Basis of Sustained High Performance. Journal of Management Studies 44:165-188.

7. Laraa F, Marquesb DP, Deveceb CA (2012) How to improve organizational results through knowledge management in knowledge-intensive business services. The Service Industries Journal 32: 1853-1863.

8. Zack M, McKeen J, Singh S (2009) Knowledge management and organizational performance: an exploratory analysis. Journal of Knowledge Management 13 392-409.

9. Schiuma G (2012) Managing knowledge for business performance improvement. Journal of Knowledge Management 16: 515-522.

10. Drucker P (1993) Post-Capitalist Society. Harper Collins, New York, NY

11. King J (1993) Editorial notes. Information Systems Research 4: 291-298

12. Galup SD, Dattero R, Hicks RC (2002) Knowledge management systems: An Architecture for active and passive knowledge. Information Resource Management Journal 15: 22-27.

13. Bourdreau A, Couillard G (1999) System integration and knowledge management. Information Systems Management 16: 24-32.

14. Lang JC (2001) Managerial concerns in knowledge management. Journal of Knowledge Management 5: 43-59.

15. Nonaka I, Takeuchi H (1995) The Knowledge Creation Company: How Japanese Companies Create the Dynamics of Innovation. Oxford University Press, New York, NY.

16. Davenport TH, Prusak L (1998) Working Knowledge: How Organizations Manage what they Know. Harvard Business School Press, Boston, MA.

17. Kantner J (1999) Knowledge management, practically speaking. Information Systems Management. Fall 16: 7-15.

18. Polanyi M (1962) Personal Knowledge: Towards a Post-Critical Philosophy corrected. (ed), University of Chicago Press, Chicago, IL.

19. Li M, Gao F (2003) Why Nonaka highlights tacit knowledge: a critical review. Journal of Knowledge Management 7: 6-14.

20. Ragsdell G (2009) Managing Knowledge about Knowledge Management: Practicing What We Teach. Innovation in Teaching and Learning in Information and Computer Sciences 8: 21-26.

21. Gartner Group (1999) White papers on knowledge management. Gartner Group, Stanford, CT.

\section{Paquette $S$ (2006) Customer Knowledge Management.}

23. Xu J, Quaddus M (2012) Examining a model of knowledge management systems adoption and diffusion: a partial least square approach. KnowledgeBased Systems 27: 18-28.

24. Alavi M, Leidner DE (2001) Review: Knowledge management and knowledge management systems: conceptual foundations and research issues. MIS Quarterly 25: 107-136

25. Margaryan A, Milligan C, Littlejohn A (2011) Validation of Davenport's classification structure of knowledge-intensive processes. Journal of Knowledge Management 15: 568-581.

26. De Pablos PO (2002) Knowledge management and organizational learning: Typologies of knowledge strategies in the Spanish manufacturing industry from 1995 to 1999. Journal of Knowledge Management 6: 52-62.

27. Cebi F, Aydin OF, Gozlu S (2010) Benefits of Knowledge Management in Banking. Journal of Transnational Management 15: 308-321.

28. Kridan AB, Goulding JS (2006) A case study on knowledge management implementation in the banking sector. The Journal of Information and Knowledge Management Systems 36: 211-222.

29. Lee EJ, Kim HS, Kim HY (2014) Relationships between core factors of knowledge management in hospital nursing organizations and outcomes of nursing performance. Journal of Clinical Nursing 23: 3513-3524.

30. Chang SC, Lee MS (2008) The linkage between knowledge accumulation capability and organizational innovation. Journal of Knowledge Management 12: 3-20.

31. Mills AM and Smith TA (2011) Knowledge management and organizationa performance: a decomposed view. Journal of Knowledge Management 15: 156-171.

32. Ollodude OO, Olladejio BF (2013) Enhanced Customer-based Knowledge Management System for Products Generation in Banking system. Anale Seria Informatica 11: 129-137.

33. Tanriverdi H (2005) Information technology relatedness, knowledge management capability, and performance of multibusiness firms. MIS Quarterly 29: 311-334.

34. Davenport TH, Volpel SC (2001) The rise of knowledge towards attention management. Journal of Knowledge Management 5: 212-221.

35. Paisittanand A, Digman LA, Lee SM (2007) Managing knowledge capabilities for strategy implementation effectiveness. International Journal of Knowledge Management 3: 84-110.

36. Carrillo PM, Robinson HS, Anumba CJ, Al-Ghassani AM (2003) IMPaKT: A framework for linking knowledge management to business performance. Electronic Journal of Knowledge Management 1: 1-12.

37. Gold AH, Malhotra A, Segars AH (2001) Knowledge management: an organizational capabilities perspective. J Manage Inf Syst 18: 185-214.

38. Lee S, Kim BG, Kim H (2012) An integrated view of knowledge management for performance. Journal of Knowledge Management 16: 183-203.

39. Buchel B, Probst G (2000) From organizational learning to knowledge management.

40. Iftikhar Z (2003) Developing an instrument for knowledge management project evaluation. Electronic Journal of Knowledge Management 1: 55-62.

41. Sanchez R (2005) Knowledge management and organizational learning Fundamental concepts for theory and practice. Lund Institute of Economic Research Working Paper Series 3: 1-32.

42. Seleim A Khalil O (2007) Knowledge management and organizationa performance in the Egyptian software firms. International Journal of Knowledge Management 3: 37-66.

43. Ndlela LT, DuToit ASA (2001) Establishing a knowledge management programme for competitive advantage in an enterprise. International Journal of Information Management 21: 151-165.

44. Roberts J (2000) From know-how to show-how? Questioning the role of information and communication technologies in knowledge transfer. Technology Analysis and Strategic Management 12: 429-443.

45. Rao M (2004) Overview: the social life of KM tools. In Rao M (Ed), KM Tools 
Citation: Rashed MS (2016) The Readiness of Banks in Knowledge Management: A Study of Three Private Commercial Banks in Bangladesh. J Bus Fin Aff 5: 181. doi:10.4172/2167-0234.1000181

Page 5 of 5

and Techniques: Practitioners and Experts Evaluate KM Solutions, ButterworthHeinemann, Oxford, pp: 1-73.

46. Handzic M (2004) Knowledge Management: Through the Technology Glass. World Scientific Publishing, Toh Tuck Link, Singapore 2: 3-19.

47. Alavi M, Kayworth TR, Leidner DE (2005-2006) An empirical examination of the influence of organizational culture on knowledge management practices. Journal of Management Information 22: 191-224.

48. Ho CT (2009) The relationship between knowledge management enablers and performance. Industrial Management \& Data Systems 109: 98-117.

49. Rai RK (2011) Knowledge management and organizational culture: a theoretical integrative framework. Journal of Knowledge Management 15: 779-801.

50. Tseng ShM (2010) The correlation between organizational culture and knowledge conversion on corporate performance. Journal of Knowledge Management 14: 269-284.

51. Huysman M, DeWit D (2003) A critical evaluation of knowledge management practices. In Ackerman M, Pipek V, Wulf V (Eds), Sharing Knowledge - Beyond Knowledge Management. MIT Press, Cambridge, MA pp: 27-55.

52. Lee $H$, Choi $B$ (2003) Knowledge management enablers, processes, and organizational performance: An integrated view and empirical examination Journal of Management Information Systems 20: 179-228.

53. Herath SK (2007) A framework for management control research. Journal of Management Development 26: 895-915

54. Beveren JV (2003) Does health care for knowledge management? Journal of Knowledge Management 7: 90-95.

55. Klein DA (1998) Chapter 1-The Strategic Management of Intellectual Capital: An Introduction. Butterworth-Heinemann, Woburn, MA pp: 1-7.

56. Carpenter MA, Fredrickson JW (2001) Top management teams, global strategic posture, and the moderating role of uncertainty. Academy of Management Journal 44: 533-545

57. Ruggles RL (1998) The state of the notion: knowledge management in practice. California Management Review 40: 80-89.

58. O'Dell C, Grayson CJ (1999) Knowledge transfer: discover your value proposition. Strategy and Leadership 27: 10-15.

59. Feijooa HMP, Ordaza MG, Lópeza FJM (2015) Barriers for the implementation of knowledge management in employee portals. Procedia Computer Science 64: $506-513$ 